\title{
Comparison between curcumin and all-trans retinoic acid in the osteogenic differentiation of mouse bone marrow mesenchymal stem cells
}

\author{
MAHMOUD F. AHMED ${ }^{1,2}$, AHMED KAMEL EL-SAYED ${ }^{2}$, HAO CHEN $^{3}$, RUIFENG ZHAO $^{1}$, \\ MOHAMED S. YUSUF ${ }^{2}$, QISHENG ZUO ${ }^{1}$, YANI ZHANG ${ }^{1}$ and BICHUN LI $^{1}$ \\ ${ }^{1}$ Key Laboratory of Animal Breeding, Reproduction and Molecular Design of Jiangsu Province, \\ College of Animal Science and Technology, Yangzhou University, Yangzhou, Jiangsu 225009, P.R. China; \\ ${ }^{2}$ College of Veterinary Medicine, Suez Canal University, Ismailia 41522, Egypt; ${ }^{3}$ Department of Orthopedics, \\ The First Affiliated Hospital of Soochow University, Suzhou, Jiangsu 215006, P.R. China
}

Received August 15, 2018; Accepted March 6, 2019

DOI: $10.3892 / \mathrm{etm} .2019 .7414$

\begin{abstract}
The use of bone marrow mesenchymal stem cells (BMSCs) has great potential in cell therapy, particularly in the orthopedic field. BMSCs represent a valuable renewable cell source that have been successfully utilized to treat damaged skeletal tissue and bone defects. BMSCs can be induced to differentiate into osteogenic lineages via the addition of inducers to the growth medium. The present study examined the effects of all-trans retinoic acid (ATRA) and curcumin on the osteogenic differentiation of mouse BMSCs. Morphological changes, the expression levels of the bone-associated gene markers bone morphogenetic protein 2 , runt-related transcription factor and osterix during differentiation, an in vitro mineralization assay, and changes in osteocalcin expression revealed that curcumin supplementation promoted the osteogenic differentiation of BMSCs. By contrast, the application of ATRA increased osteogenic differentiation during the early stages, but during the later stages, it decreased the mineralization of differentiated cells. In addition, to the best of our knowledge, the present study is the first to examine the effect of curcumin on the osteogenic potency of mouse embryonic fibroblasts (MEFs) after reprogramming with human lim mineralization protein (hLMP-3), which is a positive osteogenic regulator. The results revealed that curcumin-supplemented culture medium increased hLMP-3 osteogenic potency compared with that of MEFs
\end{abstract}

Correspondence to: Professor Bichun Li, Key Laboratory of Animal Breeding, Reproduction and Molecular Design of Jiangsu Province, College of Animal Science and Technology, Yangzhou University, 48 East Wenhui Road, Yangzhou, Jiangsu 225009, P.R. China

E-mail: yubcli@yzu.edu.cn

Key words: bone marrow mesenchymal stem cells, all-trans retinoic acid, curcumin, human lim mineralization protein-3, bone regeneration cultured in the non-supplemented medium. The present results demonstrate that enrichment of the osteogenic culture medium with curcumin, a natural osteogenic inducer, increased the osteogenic differentiation capacity of BMSCs as well as that of MEFs reprogrammed with hLMP-3.

\section{Introduction}

Bone is a calcified connective tissue formed via the differentiation of osteoprogenitor cells into mature osteoblasts. Osteoblasts, the bone forming cells, are characterized by their cuboidal appearance, and their association with bone matrix formation (1). Several reports have demonstrated the importance of bone marrow mesenchymal stem cells (BMSCs) in cell-based therapy for bone tissue regeneration and the treatment of skeletal tissue damage (2-5). BMSCs have a number of advantages, such as their great potential for proliferation and differentiation. BMSCs exhibit plasticity, and the ability to differentiate into chondrocytes, osteocytes and adipocytes in vitro and in vivo (6). In addition, BMSCs have the ability to secrete biological factors with paracrine regenerative and anti-inflammatory effects (7). The differentiation of BMSCs in vitro is reliant on the culture conditions; for example, osteogenic medium (OM) supplemented with dexamethasone, ascorbic acid and $\beta$-glycerol phosphate induces the differentiation of BMSCs into an osteogenic lineage (8).

All-trans retinoic acid (ATRA) is derivative of vitamin A, which is vital for important physiological processes and functions (9). A number of previous studies have reported the key role of ATRA in the regulation of bone cell function (10-12); ATRA may promote physiological bone remodeling (11). The ability of ATRA to influence osteoblast differentiation has been observed in numerous cell systems (13-19). In addition, ATRA has been reported to enhance in vitro osteogenesis in multiple cell types, including preosteoblasts (20), calvarial osteoblasts (16) and mesenchymal stem cells (MSCs) $(14,18,21,22)$. However, ATRA does not induce the osteogenic differentiation of BMSCs; dexamethasone is primarily used to initiate osteogenesis, whereas ATRA inhibits osteoblast gene 
expression and mineralization (23-25). The effect of ATRA on osteoblastogenesis and osteoclastogenesis is dependent on the differentiation marker examined, as well as the cell system employed (26). In a previous study, ATRA exerted divergent effects on osteoblastogenesis and adipogenesis in MSCs (13). ATRA may reduce the osteogenic differentiation capacity and promote the adipogenesis of mouse embryonic palate mesenchymal cells via its influence on bone morphogenetic protein (BMP) signaling (27). Studies performed in vitro and in vivo have suggested that bone may be a main target of retinoid action (10).

Curcumin has become a subject of scientific interest as a potential therapeutic agent in orthopedic fields. Curcumin is a phenolic natural product extracted from the rhizome of Curcuma longa (turmeric). It has been widely used as a dietary spice and traditional medicine for many centuries in Eastern populations as a treatment for numerous diseases (28-30). In addition, curcumin supplementation has been demonstrated to be efficient in the prevention and management of osteopenia (31). Several studies have reported its useful effects on bone health and fat metabolism (32-34). It was previously demonstrated that curcumin protects against ovariectomy-induced bone loss and decreased osteoclastogenesis in animal models (35-38). In addition, curcumin improved bone microarchitecture and increased mineral density in mice $(39,40)$. Furthermore, the therapeutic effect of curcumin has also been reported in arthritis (41). Jain et al (42) revealed that a curcumin-eluting tissue scaffold increased the mRNA and protein expression of known osteogenic markers.

At the cellular level, curcumin modulates important molecular targets that participate in the regulation of bone remodeling (43-46). The effects of curcumin on bone cells in vitro have been reported (47-52). The action of curcumin on osteoblast cells is controversial $(49,53)$. Curcumin enhanced the osteogenic differentiation of MSCs in vitro (53). By contrast, curcumin attenuated the osteogenic differentiation and calcification of rat vascular smooth muscle cells (54). Curcumin has also been revealed to activate the $\mathrm{Wnt} / \beta$-catenin signaling pathway (55-57); therefore, curcumin is considered an effective treatment for osteoporosis. However, other studies have demonstrated that curcumin suppresses this pathway $(58,59)$. Curcumin is able to improve bone health in patients with osteoporosis by acting on multiple steps in the activation and differentiation of osteoclasts, and improving mineral density and mechanical properties. The potential mechanisms that have been proposed include inhibition of nuclear factor (NF) $-\kappa B$, receptor activator of NF- $\kappa$ B ligand (RANKL), nitric oxide production, the generation of reactive oxygen species and inflammatory cytokine synthesis $(38,39,47,50,51,60,61)$.

Transdifferentiation is a process in which adult, mature and fully differentiated cells differentiate into another specific terminal cell type via the induction of lineage-specific transcription factors. Previous studies have revealed that fibroblasts can be converted into several lineages, including neurons (62), cardiomyocytes (63), hepatocytes (64) and osteoblasts $(65,66)$ via the ectopic expression of multiple lineage-specific transcription factors or microRNAs (67). Importantly, this approach has also been applied in vivo using a number of lineage-specific transcription factors (68). Several studies have reported that the growth factor human lim mineralization protein (hLMP) is directly associated with osteoblastic differentiation, and appears to be a positive regulator of bone formation (69-72). The production of multiple osteogenetic growth factors via the administration of a single therapeutic molecule amplifies osteoinductive signaling, and thus may be highly advantageous when using LMP. The different types of secreted BMPs may be mixed and potentially form heterodimeric BMPs that may have more potent osteoinductivity than homodimeric BMPs (73).

The aim of the present study was to evaluate and clarify the efficiency of the natural osteogenic modulators curcumin and ATRA during the osteogenic differentiation of mouse BMSCs, as there are numerous contradictory opinions regarding their roles during this process. Therefore, the present study tested the effect of curcumin on another osteogenic transdifferentiation model to elucidate its wide range of effects on different cell types. Mouse embryonic fibroblasts (MEFs), undergoing osteogenic reprogramming using hLMP3, as a positive regulator of osteoblast differentiation, were cultured in curcumin-enriched medium. The results revealed a significant difference in bone markers between the curcumin-enriched MEFs and the control MEFs. These findings highlight the role of curcumin in osteogenic differentiation in different cell lines.

\section{Materials and methods}

All reagents were purchased from Gibco; Thermo Fisher Scientific, Inc., (Waltham, MA, USA) unless stated otherwise in the text.

Experimental animals. A total of 25 male BALB/c mice (5-6 weeks old; body weight, 15-21 g) and 2 pregnant female C57/BL mice (12-13 weeks old; body weight, 23-26 g) at 13 days post-coitum were used throughout the present study. Animals were obtained from the Laboratory Animal Centre, Jiangsu University (Zhenjiang, China). The animals were housed in cages in a temperature-controlled room (20-25 $\mathrm{C}$ and $40-0 \%$ humidity), with a 12-h light/dark cycle and free access to commercial food and water. All procedures involving animals and their care conformed to the USA National Institutes of Health guidelines (NIH Pub. No. 85-23, revised 1996). All animal experiments were reviewed and approved by the Institutional Animal Care and Use Committee of School of Animal Science and Technology, Yangzhou University (Yangzhou, China; approval no. YZUDWSY2017-0029). The procedures were performed in accordance with the Regulations of the Administration of Affairs Concerning Experimental Animals (China, 1988), and the Standards for the Administration of Experimental Practices (Jiangsu, China; 2008).

Isolation and culture of mouse BMSCs. The isolation and culture of BMSCs was conducted as previously described (74). In brief, 5-6-week-old male BALB/c mice were sacrificed via the cervical dislocation method. The animals were then rinsed with $70 \%$ ethanol for few min. The hind limbs were excised from the trunk of the body, and the bones were kept in PBS for the subsequent steps under a sterile hood. The bones were placed on sterile gauze and were gently rubbed to remove any attached soft tissue. The epiphysis was cut, a 26-gauge syringe needle was inserted into the bone marrow cavity and 
the marrow was flushed out using Dulbecco's modified Eagle's medium (DMEM); flushing was continued until pale white bone was observed. The cell suspension was filtered through a 70-mm filter mesh to remove any bony spicules, muscle or cell clumps. The number of viable cells was counted via trypan blue staining. Cells were cultured in $95-\mathrm{mm}$ dishes using $1 \mathrm{ml}$ complete culture medium (CCM) at a density $25 \times 10^{6}$ cells $/ \mathrm{ml}$, and then kept at $37^{\circ} \mathrm{C}$ in a humidified atmosphere containing 95\% air and $5 \% \mathrm{CO}_{2}$. The CCM comprised DMEM containing $15 \%$ fetal bovine serum (FBS; HyClone; GE Healthcare Life Sciences, Logan, UT, USA), 2 mM L-glutamine and 1\% penicillin-streptomycin (Beyotime Institute of Biotechnology, Haimen, China). Cells were cultured with frequent medium changes as described previously (74). When primary cultures became nearly confluent, the culture was treated with $0.5 \mathrm{ml}$ $0.25 \%$ trypsin EDTA for $2 \mathrm{~min}$ at room temperature. The cells that were lifted within 2 min were harvested and cultured in a 60 -mm plate. Once the culture reached $70-80 \%$ confluence, the cells were harvested for successive passages. The subsequent experiments were performed with cells from passages 3 and 4 .

Isolation and culture of MEFs. Pregnant female mice (C57/BL) at 13 days post-coitum was sacrificed via the cervical dislocation method. Uterine horns were removed, washed with PBS and opened. Embryos were harvested and the head and the visceral organs were removed. After washing with PBS, the embryos were minced, and then incubated at $37^{\circ} \mathrm{C}$ for $15 \mathrm{~min}$ in $0.25 \%$ trypsin EDTA with gentle shaking. Trypsin was neutralized with an equal amount of MEF medium and cells were collected by centrifugation at $500 \mathrm{x}$ g for $7 \mathrm{~min}$ at room temperature $\left(20-25^{\circ} \mathrm{C}\right)$. Cells were then resuspended and cultured on gelatin-coated dishes with MEF growth medium containing high glucose DMEM mixed with 10\% FBS, 4 mM L-glutamine and 1:100 penicillin-streptomycin at $37^{\circ} \mathrm{C}$ with $5 \% \mathrm{CO}_{2}$. The cells were examined daily using an inverted microscope (Olympus TH4-200; Olympus Corporation, Tokyo, Japan) to assess their general appearance, and to identify any signs of microbial contamination. Once confluent, cells were passaged 1:3 and the second passage cells were trypsinized and frozen at $-80^{\circ} \mathrm{C}$. In the present experiments, MEFs within three passages were used to avoid replicative senescence.

Lentiviral vector. The codon-optimized hLMP-3 cDNA sequence obtained from Pola et al (75), was synthesized, and cloned into T-Vector pMD19 (Takara Biotechnology, Co., Ltd., Dalian, China) by GenScript (Project ID. 7162905-1; GenScript, Jiangsu, China). cDNA sequencing and the primer design of hLMP-3 were also conducted by GenScript. The construction of the viral expression vector containing the transcription factors hLMP-3 was performed by Genomeditech (Shanghai, China; Project ID. GM-Lc-01147). The primers used for hLMP-3 (Accession number: AAK30569.1) were as follows: Forward, 5'-CCCTCGAGGGCTTGGCCATGGATA GTTTCAAGGTGGTC-3' and reverse, 5'-GCGTCGACGTTC AGCCACTTGAGGCGGGCATCTG-3' (restriction recognition sites are underlined).

Characterization of mouse BMSCs. BMSCs (passage 3) were used for MSC cell surface marker experiments. The MSC surface markers cluster of differentiation (CD)44 and CD90, and also the hematopoietic marker CD45 were examined by flow cytometry as previously described (76,77). Briefly, cells at passage 3 were harvested using trypsin/EDTA. Following cell counting, cell suspensions were stained with the following fluorescence-conjugated antibodies: Fluorescein isothiocyanate (FITC)-anti-mouse/human CD44 antibody (1:100; cat. no. 103021; BioLegend, Inc., San Diego, CA, USA), FITC anti-mouse CD45 monoclonal antibody (1:100; cat. no. 11-0451; eBioscience; Thermo Fisher Scientific, Inc.) and FITC anti-mouse CD90 monoclonal antibody (1:100; cat. no. 11-0903; eBioscience; Thermo Fisher Scientific, Inc.) for $1 \mathrm{~h}$ at $4^{\circ} \mathrm{C}$. Cells stained with FITC-labeled rat anti-mouse immunoglobulin G (IgG; 1:100; cat. no. 406001; BioLegend, Inc.) served as controls. Cells were pelleted, washed twice with PBS and fixed with $1 \%$ paraformaldehyde in PBS. Cell surface antigens were detected with a flow cytometer using BD Accuri C6 Plus software (BD Biosciences, Franklin Lakes, NJ, USA).

In vitro osteogenic induction of BMSCs. BMSCs were seeded at a density of 50 cells $/ \mathrm{cm}^{2}$ and cultured until they reached $70 \%$ confluency. The CCM was then changed to OM (fresh complete medium with 15\% FBS) supplemented with $50 \mu \mathrm{g} / \mathrm{ml}$ ascorbic acid (Sigma Aldrich; Merck KGaA, Darmstadt, Germany), $10 \mathrm{mM} \beta$-glycerol phosphate disodium salt (Sigma Aldrich; Merck KGaA), and 100 nM dexamethasone (Sigma Aldrich; Merck KGaA). Cells cultured in osteogenic medium only comprised the OM group; while in the curcumin group (CR group), $15 \mu \mathrm{M}$ curcumin was added to the OM. This concentration was selected based on previous studies that used curcumin in cell culture to induce osteogenic differentiation with minimal cytotoxicity $(53,78,79)$. Curcumin was prepared according to the method previously described by $\mathrm{Gu}$ et al (53). Briefly, curcumin (Beijing Solarbio Science \& Technology Co., Ltd., Beijing, China) was dissolved in dimethyl sulfoxide and stored at $-20^{\circ} \mathrm{C}$. In the ATRA group, $1 \mu \mathrm{M}$ ATRA (Sigma-Aldrich; Merck KGaA) was added to the OM. This concentration has repeatedly been used to study the effects of ATRA on in vitro osteogenic differentiation; since the normal physiological level of ATRA is $\leq 0.01 \mu \mathrm{M}$ and the effective pharmacological concentration is $>0.1 \mu \mathrm{M}$, the $1 \mu \mathrm{M}$ concentration was selected to induce osteogenic differentiation (27,80-82).

In vitro osteogenic induction of MEFs. The protocol used was a modified version of that described by Yamamoto et al (83); the preparation and dilution of the OM components were conducted according to the protocol provided by the supplier. MEFs were re-suspended in CCM, and seeded onto 35-mm dishes (Corning ${ }^{\circledR} ; 5 \times 10^{4}$ cells/dish) or a 24-well plate (Corning ${ }^{\circledR} ; 1.2 \times 10^{4}$ cells/well) on day 1 . The next day, transduction of MEFs was performed using the supernatant containing the pGMLVPE1-hLMP-3 expression vector (multiplicity of infection=4), and supplemented with $4 \mu \mathrm{g} / \mathrm{ml}$ polybrene (Genomeditech). Following culture for $24 \mathrm{~h}$, the virus-containing medium was replaced with an OM composed of fresh complete culture medium (10\% FBS) supplemented with $50 \mu \mathrm{g} / \mathrm{ml}$ ascorbic acid, $10 \mathrm{mM} \beta$-glycerol phosphate disodium salt and $100 \mathrm{nM}$ dexamethasone. In the curcumin-supplemented group, $15 \mu \mathrm{M}$ curcumin was added to the medium. 
Reverse transcription-quantitative polymerase chain reaction $(R T-q P C R)$. Total RNA was extracted from the cell samples using TRIZOL ${ }^{\circledR}$ reagent (cat. no. 15596-026; Invitrogen; Thermo Fisher Scientific, Inc.) according to the manufacturer's protocol. Following isolation, $1 \mu \mathrm{g}$ RNA was reverse-transcribed into cDNA using FastQuant RT kits with gDNase (cat. no. KR106; Tiangen Biotech Co., Ltd., Beijing, China). The reverse transcription reaction was performed at $42^{\circ} \mathrm{C}$ for $15 \mathrm{~min}$, followed by $95^{\circ} \mathrm{C}$ for $3 \mathrm{~min}$. The cDNA samples were analyzed by RT-qPCR in a 7500 Real-Time PCR system (Applied Biosystems; Thermo Fisher Scientific, Inc.) using Super Real Premix plus (SYBR Green; cat. no. FP205; Tiangen Biotech Co., Ltd.). The thermocycling conditions for qPCR were as follows: $95^{\circ} \mathrm{C}$ for $15 \mathrm{~min}$, followed by 40 amplification cycles of $95^{\circ} \mathrm{C}$ for $10 \mathrm{sec}$ and $60^{\circ} \mathrm{C}$ for $32 \mathrm{sec}$. The sequences of the RT-qPCR primers are listed in Table I. The primers were designed and manufactured Takara Biotechnology Co., Ltd. Relative quantification was calculated with $2^{-\Delta \Delta \mathrm{Cq}}(84)$ and normalized to $\beta$-actin. Data are presented as levels relative to the expression level in the control cells.

In vitro mineralization assay. Early osteogenic differentiation was evaluated by alkaline phosphatase staining (ALP). Matrix mineralization was evaluated by Alizarin red (ALZ) and von Kossa (VK) staining. The staining intensity was quantified using Fiji in ImageJ software, version 1 (National Institutes of Health, Bethesda, MD, USA) (85).

ALP staining. Histochemical staining was performed using 5-bromo-4-chloro-3-indolyl phosphate/nitro blue tetrazolium (BCIP/NBT) ALP color development kits (cat. no. C3206; Beyotime Institute of Biotechnology) according to the manufacturer's protocol. The cells were washed with PBS buffer, then fixed with $4 \%$ formalin at room temperature for $2 \mathrm{~min}$. The cells were then washed 3 times with PBS. Following the last wash, an appropriate amount of BCIP/NBT staining solution was added, ensuring that the sample was fully covered. After the addition of the working solution, cells were incubated in the dark at $37^{\circ} \mathrm{C}$ for 5-30 min in an incubator until the desired color developed. The BCIP/NBT stain working solution was then removed, and cells were washed once or twice with distilled water to stop the color reaction.

ALZ staining. The cells were washed with $1 \mathrm{X}$ PBS, and fixed in $10 \%$ formaldehyde in $1 \mathrm{X}$ PBS for $15 \mathrm{~min}$. Following fixation, the cells washed with distilled water 2 or 3 times. Cells were incubated in $40 \mathrm{mM}$ ALZ staining solution for $5 \mathrm{~min}$ in the dark. Finally, cells were washed with distilled water 4 times to remove the excess stain. The ALZ staining solution was prepared by diluting the ALZ staining powder (cat. no. A5533; Sigma-Aldrich; Merck KGaA) in distilled water. The $\mathrm{pH}$ was adjusted to 4.1-4.3 with $10 \%$ ammonium hydroxide using a $\mathrm{pH}$ Meter (Mettler Toledo, Columbus, OH, USA).

VK staining. For VK staining, the cells were washed with PBS, fixed with $10 \%$ formalin and stained with freshly prepared $5 \%$ silver nitrate solution for $30 \mathrm{~min}$ with exposure to UV light. After washing with distilled water 3 times, the cells were treated with $5 \%$ sodium thiosulfate solution for $3 \mathrm{~min}$ to remove any remaining silver nitrate. Final washing with distilled water was repeated 3 times. The silver nitrate solution $(5 \%)$ was prepared by diluting silver nitrate powder (cat. no. GB12595-90; Beijing HenGye Zhongyuan Chemical Co., Ltd., Beijing, China) in distilled water. The same diluent was used for the preparation of a solution of sodium thiosulfate (cat. no. 217263; Sigma-Aldrich; Merck KGaA).

Fluorescent immunocytochemistry. The cells were rinsed briefly with PBS, and then fixed for 20 min with $4 \%$ paraformaldehyde in $0.1 \mathrm{M}$ phosphate buffer ( $\mathrm{pH}$ 7.4) at room temperature. The cells were permeabilized for $10 \mathrm{~min}$ with $0.1 \%$ TritonX-100 in PBS, to allow for specific antibody entrance into the cells, and then blocked for 45-60 min with $4 \%$ bovine serum albumin (BSA) in PBS at room temperature. Cells were incubated overnight (16-18 h) at $4^{\circ} \mathrm{C}$ with mouse monoclonal OCN antibody (1:500; cat. no. sc-376726; Santa Cruz Biotechnology, Inc., Dallas, TX, USA). The cells were then washed 3 times with washing buffer. This was followed by $1 \mathrm{~h}$ incubation at room temperature with the secondary antibody Alexa Fluor 647-labeled goat anti-mouse IgG (1:500; cat. no. ab150115; Abcam, Cambridge, MA, USA). Following a final round of 3 washes with the wash buffer, nuclei were counterstained using DAPI at room temperature for $5 \mathrm{~min}(1 \mathrm{mg} / \mathrm{ml}$ PBS; Invitrogen; Thermo Fisher Scientific, Inc.). Cells were examined using inverted fluorescence microscopy (Olympus TH4-200).

Western blot analysis. All steps were conducted according to the manufacturer's protocol, using a Bio-Rad system (Bio-Rad Laboratories, Inc., Hercules, CA, USA). Cell lysates were collected with RIPA buffer (cat. no. P0013B; Beyotime Institute of Biotechnology) supplemented with phenyl methane sulfonyl fluoride (Beyotime Institute of Biotechnology). Following centrifugation at $12,000 \mathrm{xg}$ at $4^{\circ} \mathrm{C}$ for $10 \mathrm{~min}$, the supernatant was collected and the protein concentration was determined using a BCA protein assay kit (Beyotime Institute of Biotechnology). Protein samples were heated for $10 \mathrm{~min}$ at $95^{\circ} \mathrm{C}$, and then separated by $10 \%$ sodium dodecyl sulfate polyacrylamide gel electrophoresis (20 $\mu \mathrm{g}$ protein/lane). Samples were then blotted onto polyvinylidene fluoride membranes (Beijing Solarbio Science \& Technology Co., Ltd.) using a Trans-Blot SD system (Bio-Rad Laboratories, Inc.). The membranes were blocked with BSA blocking buffer (cat. no. CW2143S; CWBIO, Beijing, China) at room temperature for $2 \mathrm{~h}$, and then incubated with the primary mouse monoclonal osteocalcin (OCN) antibody (1:500; cat. no. sc-376726; Santa Cruz Biotechnology, Inc.) at $4^{\circ} \mathrm{C}$ overnight. After washing three times, the corresponding secondary antibody horseradish peroxidase-labeled goat anti-mouse $\operatorname{IgG}(1: 2,000$; cat. no. 665739; Merck KGaA) was added. The membranes were incubated at $37^{\circ} \mathrm{C}$ for $2 \mathrm{~h}$ and then washed with TBST (cat. no. CW0043S; CWBIO). Bands were visualized with enhanced chemiluminescence method western blot kits (cat. no. CW0048M; CWBIO) using the FluorChem Q system (ProteinSimple, San Jose, CA, USA). $\beta$-actin (1:1,000; cat. no. AA128; Beyotime Institute of Biotechnology) was used as a loading control with overnight incubation at $4^{\circ} \mathrm{C}$. The protein band intensity was quantified using Fiji in ImageJ version $1(85)$. 
Table I. Primers used for reverse transcription-quantitative polymerase chain reaction.

\begin{tabular}{lll}
\hline Gene & \multicolumn{1}{c}{ Forward primer $\left(5^{\prime}-3^{\prime}\right)$} & \multicolumn{1}{c}{ Reverse primer $\left(5^{\prime}-3^{\prime}\right)$} \\
\hline$\beta$-actin & CATCCGTAAAGACCTCTATGCCAAC & ATGGAGCCACCGATCCACA \\
Runx2 & TGCAAGCAGTATTTACAACAGAGG & GGCTCACGTCGCTCATCTT \\
OSX & GCGACCACTTGAGCAAACATC & CGGCTGATTGGCTTCTTCTT \\
BMP-2 & TGATGTGGGGTGGAATGACT & CAGCAAGGGGAAAAGGACAC
\end{tabular}

Runx2, runt-related transcription factor 2; OSX, osterix; BMP-2, bone morphogenetic protein 2.

Statistical analysis. All quantitative data are expressed as the mean \pm standard deviation $(n=3)$. Statistical analyses were performed using SPSS software version 21 (IBM Corp., Armonk, NY, USA). Statistical significance was determined using one-way analysis of variance followed by Tukey's post hoc test. $\mathrm{P}<0.05$ was considered to indicate a statistically significant difference. For some experiments the statistical significance was determined using paired sample t-tests $(\mathrm{P}<0.05$ and $\mathrm{P}<0.01)$. GraphPad Prism software version 6 (GraphPad Software, Inc., La Jolla, CA, USA) was used to produce the graphs.

\section{Results}

Morphological and immunotyping characterization of mouse BMSCs. Bone marrow was harvested from BALB/c mice, and P3 cells were seeded into 35-mm culture dishes at a density of $25 \times 10^{6}$ cells $/ \mathrm{ml}$. BMSCs are recognized as the adherent cells derived from bone marrow and are capable of extensive proliferation, producing a fibroblastic shape. Following 15 days of culture, almost homogeneous populations of fibroblast-like cells were observed (Fig. 1A). To confirm cell identity, immunofluorescent staining was used to identify the BMSCs with the surface markers CD90 and CD44, while the surface marker CD45 was used to detect hematopoietic cell contamination. The cultured cells were positive for the MSC markers CD44 and CD90, and negative for the hematopoietic cell marker CD45 (Fig. 1B).

Morphological changes during the osteogenic differentiation of BMSCs. BMSCs were induced to differentiate into an osteogenic lineage, and were able to proliferate in vitro. The morphology of BMSCs changed following the first week of culture in OM (OM group) from their spindle-like fibroblast shape to the characteristic cuboidal morphology of primary osteoblasts. Comparable results were observed in the $\mathrm{CR}$ group. By contrast, the BMSCs cultured in CCM did not differentiate into the osteoblast lineage, and cells in the ATRA group displayed a more elongated shape, and dendrites were clearly visible (Fig. 2).

Osteogenic differentiation capacity of BMSCs following induction with curcumin and ATRA. The present study performed an in vitro mineralization assay to determine the effects of curcumin and ATRA on the onset of the osteogenic differentiation of BMSCs. ALP, ALZ and VK staining were conducted during the differentiation period. ALP activity was analyzed as an early indicator of osteogenic differentiation.
The results revealed that OM induced ALP activity in the mouse BMSCs after 7 and 14 days. The ALP staining intensity was significantly increased in the $\mathrm{CR}$ group $(\mathrm{P}<0.01$ vs. the $\mathrm{OM}$ and ATRA groups); while no significant difference was detected between the OM and ATRA groups. Matrix mineralization was detected by ALZ and VK staining. Mineralization was not clearly detected after 7 days, and was slowly developing after 14 days. However, after 21 and 28 days, the OM and CR groups exhibited positively stained mineralized nodules. Mineralization was significantly stronger in the CR group compared with the OM group. By contrast, the ATRA group did not show any signs of mineralization (Fig. 3).

Effects of curcumin and ATRA on the expression levels of bone-associated gene markers during BMSC osteogenic differentiation. In order to evaluate the molecular changes following the supplementation of the OM with curcumin and ATRA, the present study examined the expression levels of the main genes associated with osteoblastic differentiation, namely runt-related transcription factor 2 (Runx2), osterix and BMP2. These markers are well known for their roles in numerous osteoblast differentiation pathways. The expression levels of these bone markers were quantified at 7, 14 and 21 days (Fig. 4). The results revealed that curcumin-supplemented OM induced a significant upregulation of osteo-specific markers when compared with the ATRA and OM groups, and this upregulation appeared to be time-dependent. After 7 days, the CR group exhibited induced expression of osteo-specific markers when compared with the OM and ATRA groups. After 14 days, the CR group had significantly higher expression levels of the three tested markers when compared with the OM and ATRA groups $(\mathrm{P}<0.01)$. The expression levels of the markers had begun to decline in the ATRA group, and were not significantly different when compared with the OM group for Runx2 and BMP2. Notably, the OM group exhibited significantly higher $(\mathrm{P}<0.01)$ osterix expression when compared with the ATRA group. These results were consistent with the results of the mineralization assay, which revealed the inhibitory effect of ATRA during the differentiation process. Finally, after 21 days, the results revealed that the CR group had upregulated levels of the three markers when compared with the OM and ATRA groups $(\mathrm{P}<0.01)$. In addition, the expression levels of osteo-specific markers in the ATRA group appeared to decline further compared with those in the OM group. These RT-qPCR results demonstrated the positive effect of curcumin-supplemented medium on the osteogenic differentiation of BMSCs. By contrast, ATRA supplementation exhibited an inhibitory effect. 


\section{A a}

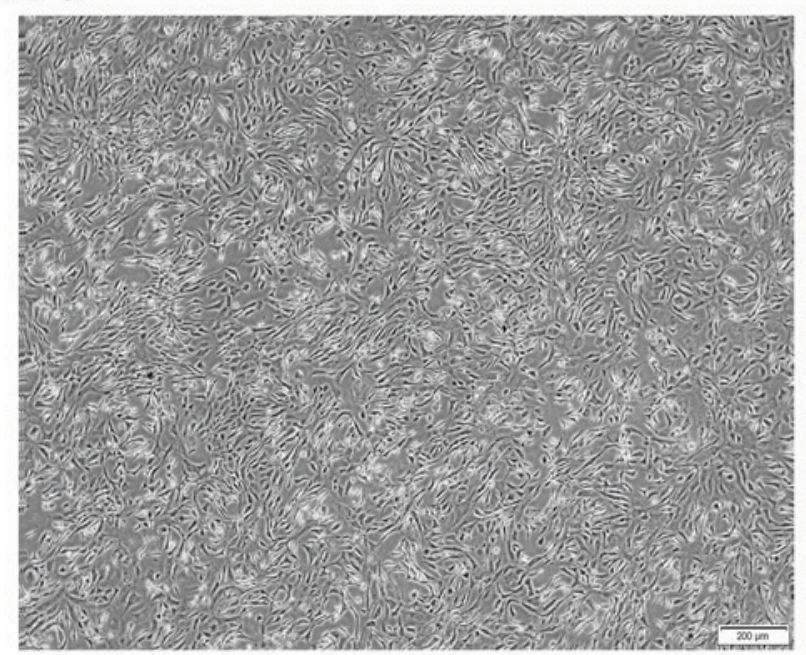

B a

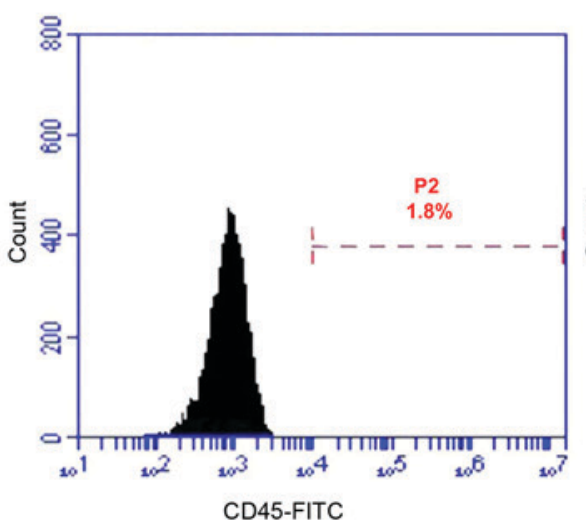

b

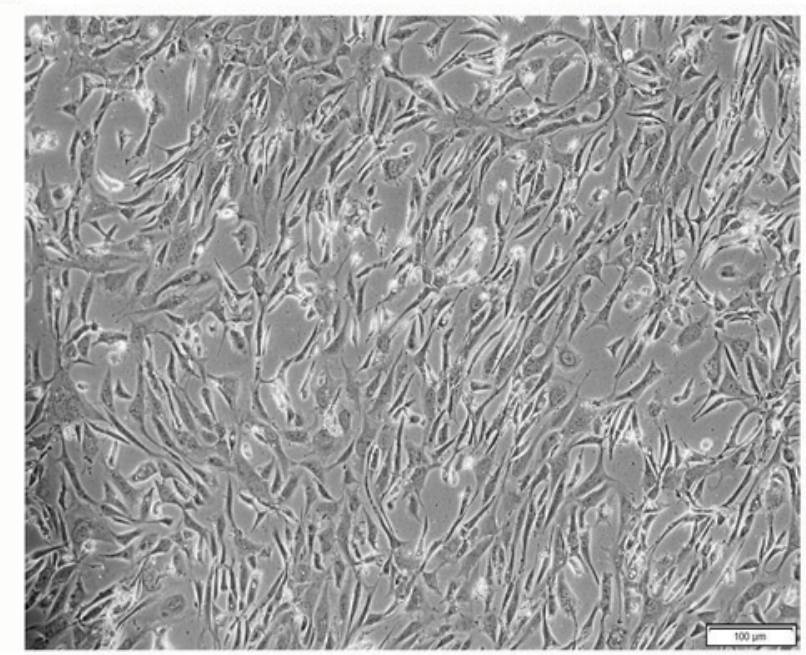

C

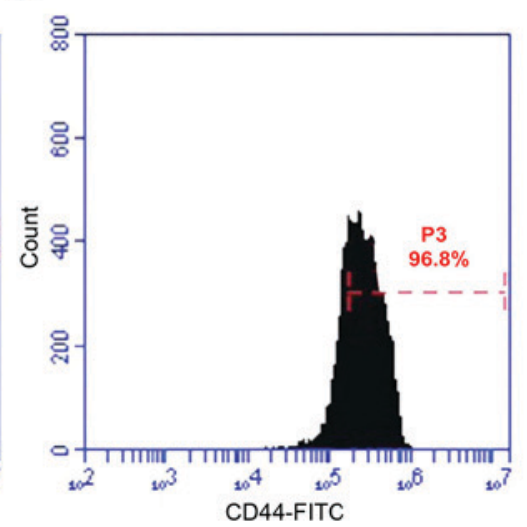

Figure 1. Characterization of mouse BMSC culture. (A) BMSCs at P3 were characterized by their fibroblastic shape: (a) Magnification, x40; (b) magnification, x100. (B) Flow cytometric analysis of mouse BMSCs at P3: Cells were (a) negative for the CD45 surface marker of hematepiotic cells, (b) positive for the MSC surface marker CD90 and (c) positive for the MSC surface marker CD44. BMSC, bone marrow mesenchymal stem cell; MSC, mesenchymal stem cell; P3, cells at passage 3 ; CD, cluster of differentiation; FITC, fluorescein isothiocyanate.

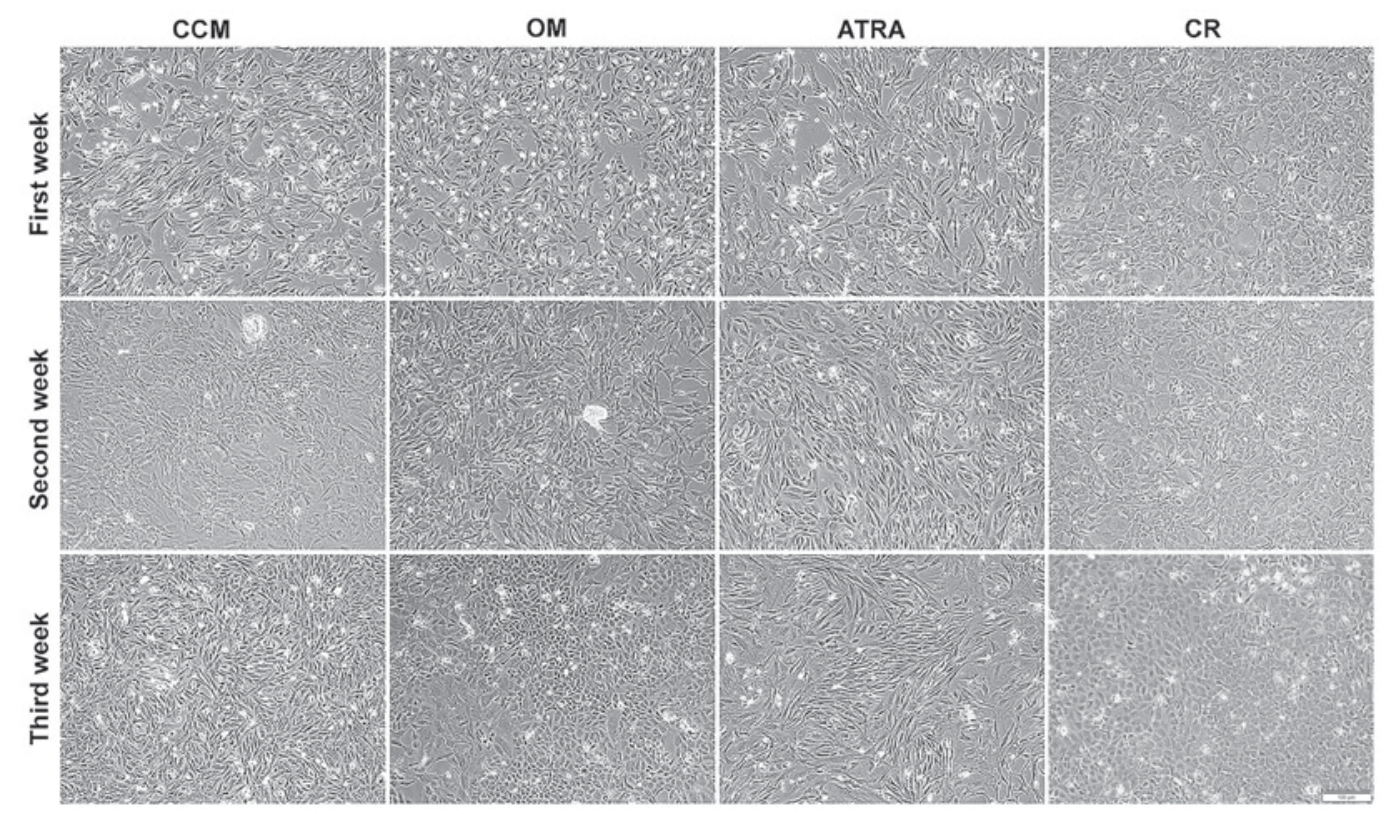

Figure 2. Morphological changes of BMSCs during osteogenic differentiation. BMSCs were divided into four groups: CCM, OM, ATRA and CR. BMSCs, bone marrow mesenchymal stem cells; CCM group, BMSCs cultured in complete culture medium; OM group, BMSCs cultured in osteogenic medium; ATRA group, BMSCs cultured in osteogenic medium supplemented with $1 \mu \mathrm{M}$ all-trans retinoic acid; CR group, BMSCs cultured in osteogenic medium supplemented with $15 \mu \mathrm{M}$ curcumin (Scale bar: $100 \mu \mathrm{m}$ ). 

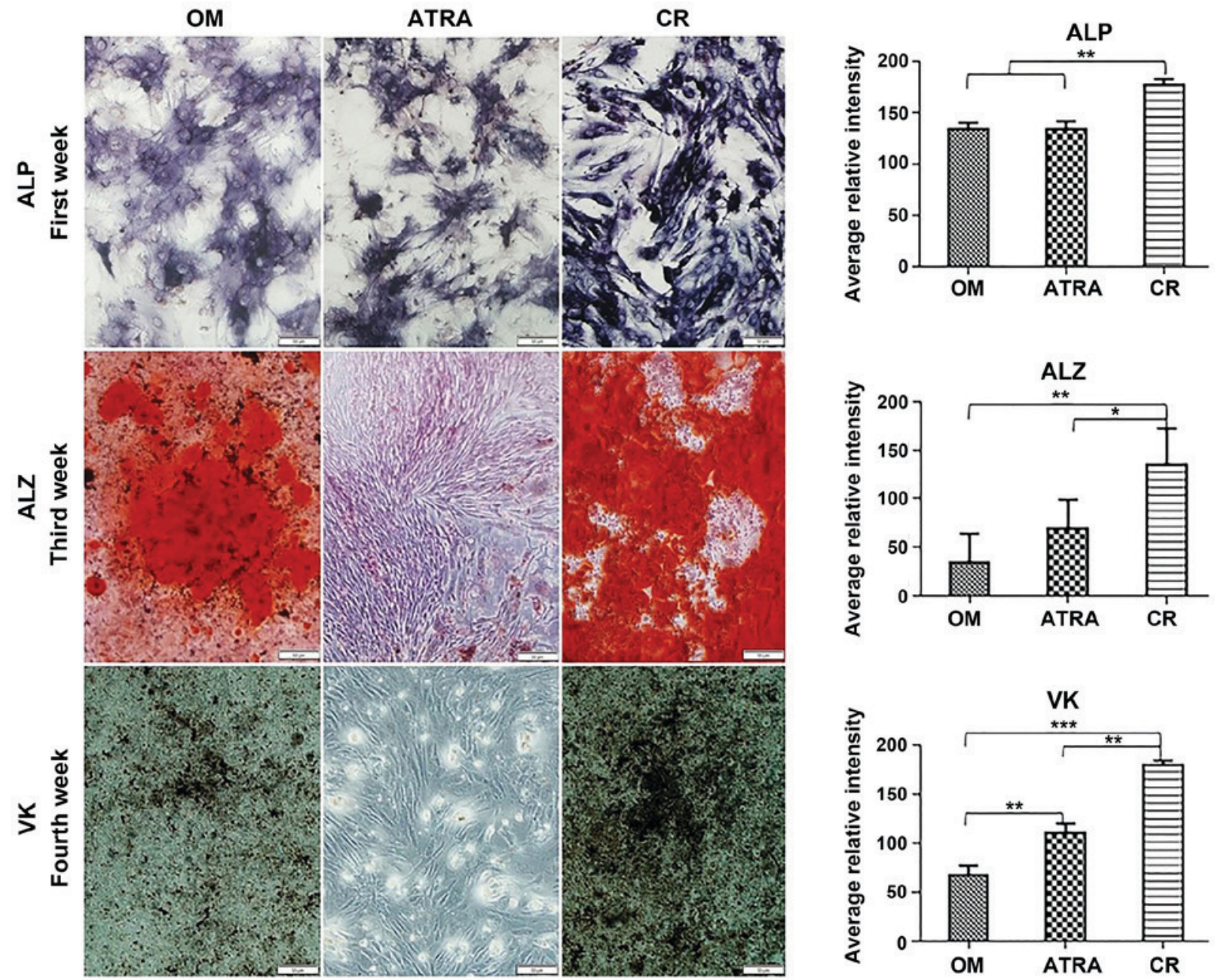

Figure 3. In vitro mineralization assay of BMSCs during osteogenic differentiation following induction with curcumin and ATRA. ALP staining results were obtained 1 week post-induction, ALZ staining was performed 3 weeks post-induction and VK staining was conducted 4 weeks post-induction. The level of calcium deposition and, in turn, the extent of mineralization was higher in the CR group than in the OM and ATRA groups. By contrast, the ATRA group did not present any symptoms of mineralization. Quantification of ALP, ALZ and VK staining intensity was performed with Fiji in ImageJ software. Quantitative data are expressed as the mean \pm standard deviation $(n=3)$. Statistical significance was determined using one-way analysis of variance, followed by Tukey's post hoc test for multi-group comparisons. ${ }^{*} \mathrm{P}<0.05,{ }^{* *} \mathrm{P}<0.01$ and ${ }^{* * *} \mathrm{P}<0.001$. BMSCs, bone marrow mesenchymal stem cells; OM group, BMSCs in osteogenic medium; CR group, BMSCs in osteogenic medium + curcumin; ATRA group, BMSCs in osteogenic medium + ATRA; ATRA, all-trans retinoic acid; ALP, alkaline phosphatase; ALZ, Alizarin red; VK, von Kossa.

Expression of OCN during the osteogenic differentiation process. OCN, a marker of mature osteoblasts, was evaluated during the differentiation process using immunostaining and the protein levels of $\mathrm{OCN}$ were determined by western blot analysis. In line with the previous results, the CR group exhibited a distinct increase in the expression level of OCN when compared with the OM and ATRA groups. Furthermore, the addition of ATRA inhibited the induction of OCN expression (Fig. 5).

Effect of curcumin-supplemented OM on the osteogenic differentiation of lentivirus-transduced MEFs with hLMP-3. The aforementioned results reveal the positive role of curcumin-supplemented medium on the osteogenic differentiation of BMSCs. Therefore, the present study investigated whether this positive role could be applied in other cell types. In a previous study, the present research team studied the reprogramming of MEFs to osteoblast cells using hLMP-3 (86). The results revealed that the transduction of MEFs with a lentiviral vector expressing the osteogenic factor
hLMP-3 induced osteoblast cell formation in vitro (86). The present study examined the effect of curcumin enrichment on the osteogenic differentiation of MEFs reprogrammed with the osteogenic factor hLMP-3. MEFs were successfully transduced with pGMLVPE1-hLMP-3, as previously reported (86). At 2 days post-transduction, the culture medium was changed to OM supplemented with curcumin. The effect of curcumin-supplemented medium was compared with that of the non-supplemented medium using RT-qPCR to detect the difference in the expression of bone markers between the two groups. The RT-qPCR results revealed that the addition of curcumin to the OM upregulated the expression of the bone markers Runx2, BMP and osterix at 7,14 and 21 days post-transduction (Fig. 6).

\section{Discussion}

In the present study, the effects of two natural compounds on the in vitro osteogenic differentiation of BMSCs were 

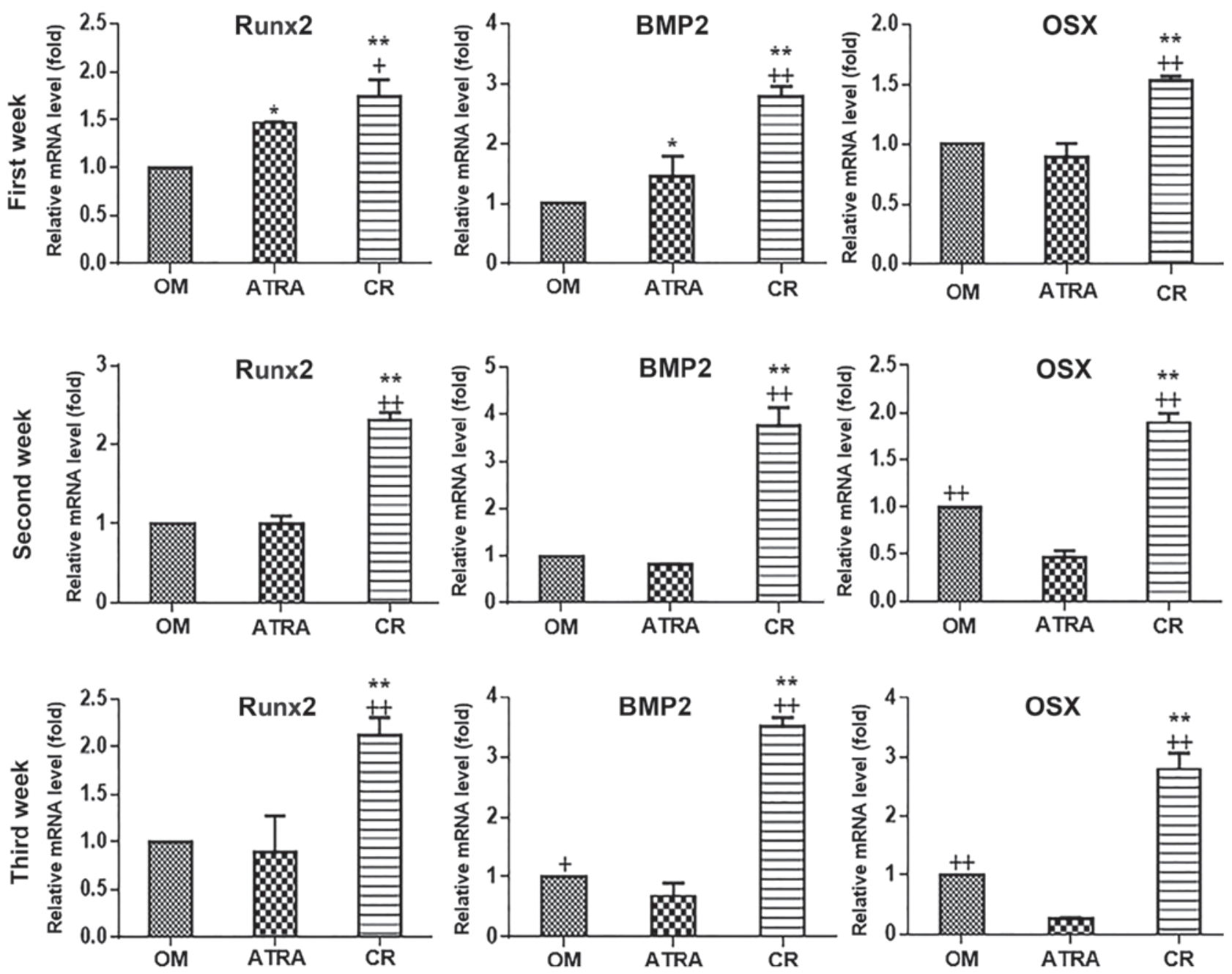

Figure 4. Expression level changes in bone specific markers during the differentiation of BMSCs to osteoblast cells. Quantification of the bone specific factors determined by reverse transcription-quantitative polymerase chain reaction at different time points. Quantitative data are expressed as the mean \pm standard deviation $(n=3)$. Statistical significance was determined using one-way analysis of variance followed by Tukey's post hoc test for multi-group comparisons. ${ }^{*} \mathrm{P}<0.05$ and ${ }^{* *} \mathrm{P}<0.01$ vs. OM group; ${ }^{+} \mathrm{P}<0.05$ and ${ }^{++} \mathrm{P}<0.01$ vs. ATRA group. BMSCs, bone marrow mesenchymal stem cells; OM group, BMSCs in osteogenic medium; CR group, BMSCs in osteogenic medium + curcumin; ATRA group, BMSCs in osteogenic medium + ATRA; ATRA, all-trans retinoic acid; Runx2, runt-related transcription factor 2; BMP2, bone morphogenetic protein 2; OSX, osterix.

investigated. BMSCs were isolated from the bone marrow of $\mathrm{BALB} / \mathrm{c}$ mice, and the osteogenic differentiation of the BMSCs to osteoblasts was induced using a standard protocol. In certain treatment groups, the OM was supplemented with $15 \mu \mathrm{M}$ curcumin (the CR group) or $1 \mu \mathrm{M}$ ATRA (the ATRA group). Cells were examined for osteogenic differentiation to determine the effect of curcumin or ATRA. Curcumin supplementation was revealed to increase the osteogenic differentiation capacity of BMSCs, as detected by the mineralization assay and RT-qPCR analysis of bone markers and OCN expression. By contrast, ATRA downregulated the osteogenic differentiation of BMSCs. To determine if the positive effect of curcumin also occurred in other cell types, curcumin was added to the culture medium during MEF reprogramming to osteoblasts using the osteogenic factor hLMP-3. Again, an elevated expression of all the bone markers was observed when compared with hLMP-3 transduced cells cultured in OM without curcumin supplementation.

The effect of ATRA on osteogenic differentiation is currently unclear in the literature, and whether its effect is pro-osteogenic, involved in delaying osteogenesis, or even anti-osteogenic is unknown $(12,14,16,20,87)$. In the present study, ATRA increased ALP expression during the mineralization assay in the first week. Later, during the differentiation process, a decreased expression of the bone markers was observed, as well as the inability to develop matrix mineralization. All these findings indicate that ATRA served a negative role during the osteogenic differentiation of BMSCs. These results are consistent with those of previous studies $(27,82)$, which suggested that this inhibitory effect of ATRA is mediated via BMP signaling. They reported that ATRA upregulated the expression of BMP-receptor IA which is responsible for adipogenic differentiation, and reduced the expression of BMP-receptor IB, which is responsible for the osteogenic differentiation of BMSCs. Another explanation posed by Green et al (88) is that retinoic acid receptor (RAR) agonists, such as ATRA, impair osteogenesis through RAR $\alpha$ and RAR $\gamma$, which may explain why high intake and serum levels of retinol are associated with fracture risk. By contrast, several studies have demonstrated the positive role 

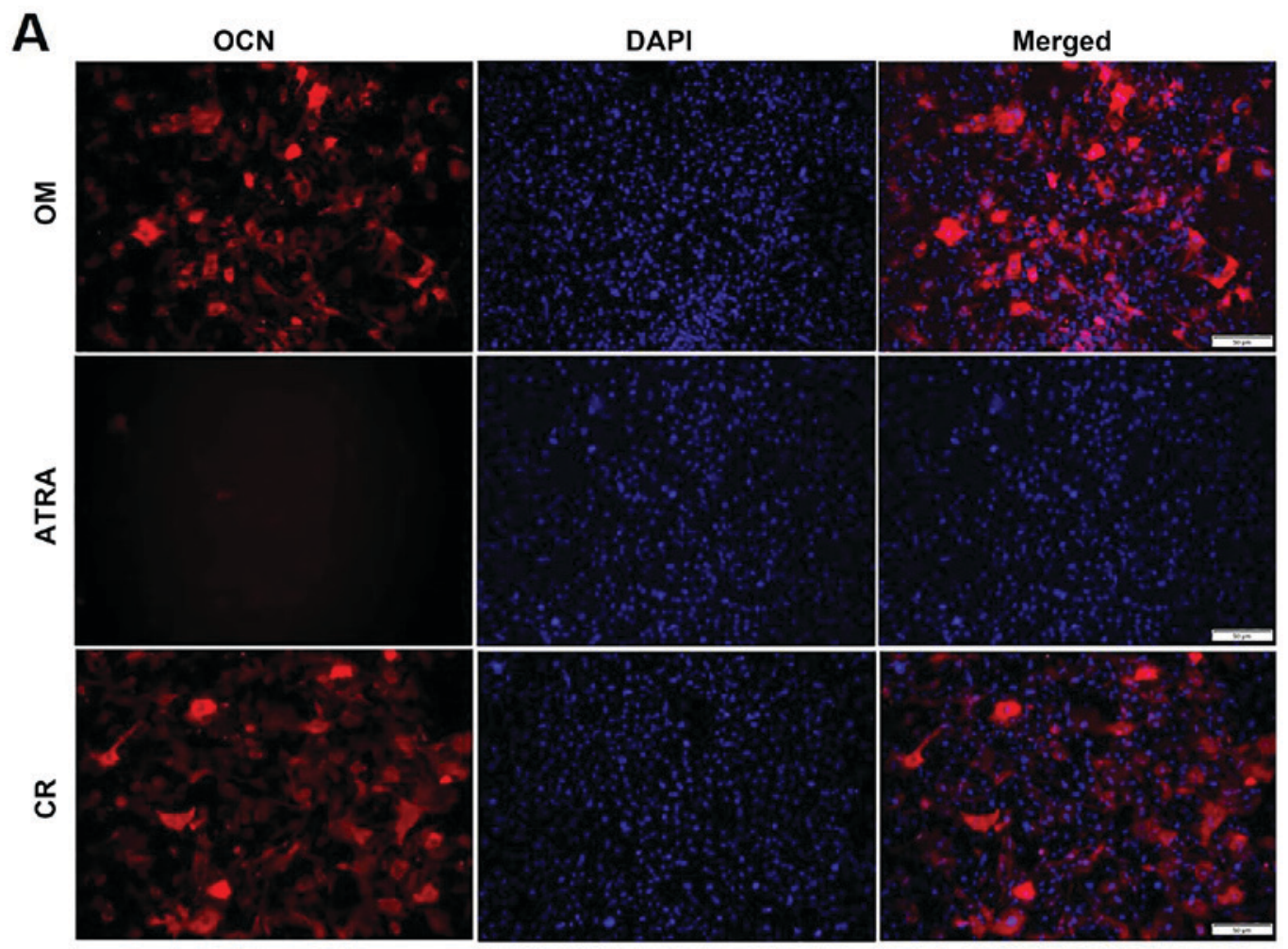

B

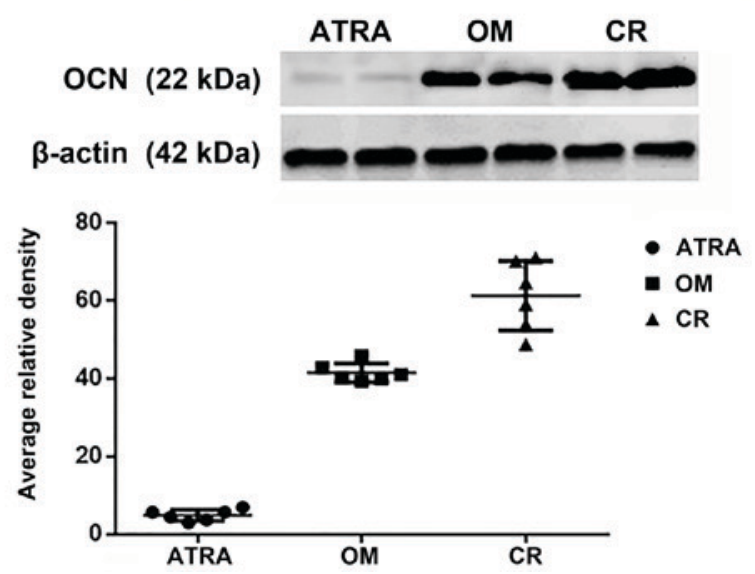

Figure 5. Effect of curcumin and ATRA on OCN expression in BMSCs at 28 days post-osteogenic differentiation. (A) BMSCs cultured in different media were immunostained with the specialized marker of late osteoblast differentiation, OCN. Scale bar, $50 \mu \mathrm{m}$. (B) The protein expression of OCN was evaluated using western blot analysis. $\beta$-actin served as an internal control. The mean relative density of the OCN bands was measured using Fiji in ImageJ software. The mean and standard deviation are presented. BMSCs, bone marrow mesenchymal stem cells; OM group, BMSCs in osteogenic medium; CR group, BMSCs in osteogenic medium + curcumin; ATRA group, BMSCs in osteogenic medium + ATRA; ATRA, all-trans retinoic acid; OCN, osteocalcin.

of ATRA during the osteogenic differentiation of cell types other than BMSCs $(18,89,90)$. In the present study, BMSCs treated with ATRA did not express OCN, which is the main non-collagenous protein of bone. This may be explained by interactions between ATRA and the OCN promotor (91).

In the present study, curcumin upregulated the osteogenic differentiation of BMSCs. Several studies have examined the role of curcumin in the orthopedic field (35-38). The present results were consistent with those of Gu et al (53), who reported that curcumin increased the osteoblast differentiation of rat MSCs with a reduction in adipocytes. The authors considered that this increase occurred due to an increase in HO-1 expression induced by curcumin, which in turn promoted osteoblast differentiation. In the same context, Son et al (92) reported that curcumin increased the expression of genes such as Dlx5,
Runx2, ALP and OCN, which subsequently induced osteoblast differentiation in $\mathrm{C} 3 \mathrm{H} 10 \mathrm{~T} 1 / 2$ cells. These findings were interpreted through a new hypothesis, which is that curcumin induced mild ER stress, similar to BMP2 functioning, in osteoblast cells. Furthermore, Son et al (92) reported that curcumin is similar to BMP2 as it induces the phosphorylation of Smad 1/5/9. By contrast, another study revealed that the administration of curcumin did not efficiently improve bone mineralization in ovariectomized rats, and indicated that curcumin affected the level of osteogenesis commitment, not osteoblast maturation (36). It has also been revealed that curcumin reduces the expression of RANKL and inhibits osteoclastogenesis by acting on BMSCs (61). This could be explained by the activity of curcumin as a scavenger of reactive oxygen species. Upregulation of RANKL induced by estrogen 

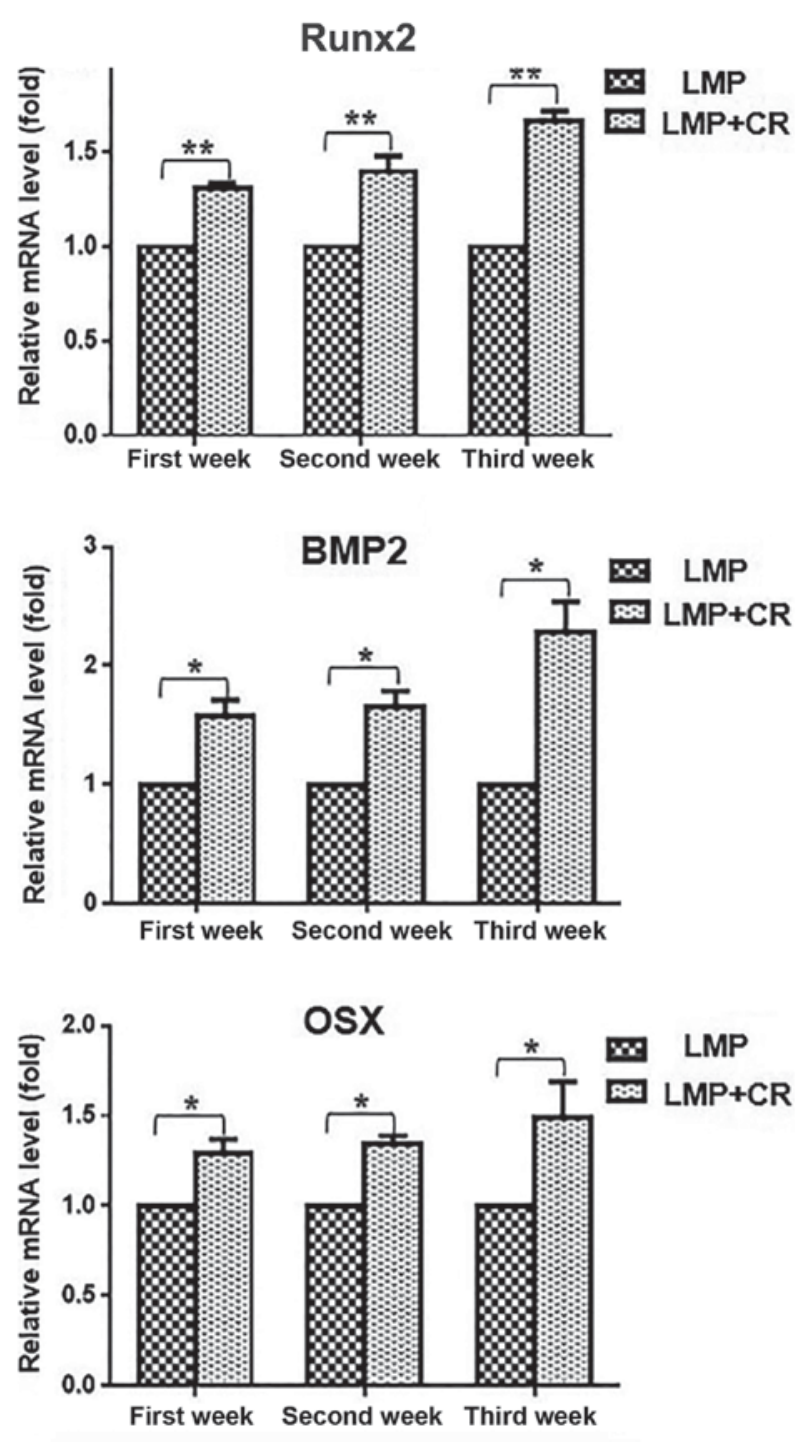

Figure 6. Expression level changes of bone-specific markers during the osteogenic reprogramming of mouse embryonic fibroblasts using the osteogenic factor hLMP-3 with and without curcumin enrichment. Quantification of the bone specific factors by reverse transcription-quantitative polymerase chain reaction at different time points (1,2 and 3 weeks) post-transduction. The quantitative data are expressed as the mean \pm standard deviation $(\mathrm{n}=3)$ Statistical significance was determined using a paired sample t-test. $\mathrm{P}<0.05$ and ${ }^{* *} \mathrm{P}<0.01$. hLMP-3, human lim mineralization protein 3; CR, curcumin; LMP + CR group, MEFs reprogrammed with hLMP- 3 and cultured in medium supplemented with $15 \mu \mathrm{M}$ curcumin; LMP group, MEFs reprogrammed with hLMP-3 without curcumin supplementation; Runx2, runt-related transcription factor 2; BMP2, bone morphogenetic protein 2; OSX, osterix.

deficiency in humans results in increased bone resorption (93). In addition to RANKL inhibition, curcumin also inhibits $\mathrm{NF}-\kappa \mathrm{B}$ (47), which is associated with impaired bone formation in osteoporosis, and inhibits the differentiation and mineralization of mature osteoblasts. The inhibition of NF- $\mathrm{KB}$ results in stimulation of the differentiation and mineralization of primary murine BMSCs and pre-osteoblasts $(94,95)$. Thus, curcumin may enhance osteogenesis through its interactions with NF- $\kappa$ B. Curcumin has also been demonstrated to affect other signaling pathways associated with bone remodeling, including the Wnt (96) and transforming growth factor- $\beta$ signaling pathways (97).
In conclusion, the results of the present study highlight the potential use of some natural osteogenic inducers in the orthopedic field. The positive role of curcumin during the osteogenic differentiation of BMSCs was demonstrated, and curcumin was revealed to be capable of enriching the osteogenic differentiation of other cell types, namely, MEFs reprogrammed with hLMP-3. By contrast, the use of ATRA inhibited the osteogenic differentiation process of BMSCs rather, which is contrary to its important role in the osteogenic induction of other cell types.

\section{Acknowledgements}

The authors would like to thank the members of the Key Laboratory of Animal Breeding, Reproduction and Molecular Design for Jiangsu Province, College of Animal Science and Technology, Yangzhou University, China for their help with the isolation of BMSCs and MEFs, and also for taking care of the laboratory animals during the study period.

\section{Funding}

The present study was funded by National Natural Science Foundation of China (grant nos. 31472087 and 31572390), College Students' Innovation and Entrepreneurship Training Program, Yangzhou University (grant no. X20170702), the Project Funded by the Priority Academic Program Development of Jiangsu Higher Education Institutions, the Key Research and Development Program (grant no. 2017YFE0108000) and the High Level Talents Q7 Support Program of Yangzhou University.

\section{Availability of data and materials}

The datasets used and/or analyzed during the current study are available from the corresponding author on reasonable request.

\section{Authors' contributions}

MFA and AKE have performed the experiments, contributed to data analysis and wrote the manuscript. HC substantially contributed to the interpretation of data and revision of the manuscript. RZ and QZ contributed to the study conception, and analysis and interpretation of data. MSY, YZ and BL conceived and designed the study, and approved the final version to be published.

\section{Ethics approval and consent to participate}

All animal experiments were reviewed and approved by the Institutional Animal Care and Use Committee of School of Animal Science and Technology, Yangzhou University (Yangzhou, China; approval no. YZUDWSY2017-0029).

\section{Patient consent for publication}

Not applicable.

\section{Competing interests}

The authors declare that they have no competing interests. 


\section{References}

1. Wrobel E, Leszczynska J and Brzoska E: The characteristics of human bone-derived cells (HBDCS) during osteogenesis in vitro. Cell Mol Biol Lett 21: 26, 2016.

2. Bianco P, Riminucci M, Gronthos S and Robey PG: Bone marrow stromal stem cells: Nature, biology, and potential applications. Stem Cells 19: 180-192, 2001.

3. Kon E, Muraglia A, Corsi A, Bianco P, Marcacci M, Martin I, Boyde A, Ruspantini I, Chistolini P, Rocca M, et al: Autologous bone marrow stromal cells loaded onto porous hydroxyapatite ceramic accelerate bone repair in critical-size defects of sheep long bones. J Biomed Mater Res 49: 328-337, 2000.

4. Petite H, Viateau V, Bensaïd W, Meunier A, de Pollak C, Bourguignon M, Oudina K, Sedel L and Guillemin G: Tissue-engineered bone regeneration. Nat Biotechnol 18: 959-963, 2000

5. Quarto R, Mastrogiacomo M, Cancedda R, Kutepov SM, Mukhachev V, Lavroukov A, Kon E and Marcacci M: Repair of large bone defects with the use of autologous bone marrow stromal cells. N Engl J Med 344: 385-386, 2001.

6. Beresford JN, Bennett JH, Devlin C, Leboy PS and Owen ME: Evidence for an inverse relationship between the differentiation of adipocytic and osteogenic cells in rat marrow stromal cell cultures. J Cell Sci 102: 341-351, 1992.

7. Caplan AI: Adult mesenchymal stem cells for tissue engineering versus regenerative medicine. J Cell Physiol 213: 341-347, 2007.

8. Jaiswal N, Haynesworth SE, Caplan AI and Bruder SP: Osteogenic differentiation of purified, culture-expanded human mesenchymal stem cells in vitro. J Cell Biochem 64: 295-312, 1997.

9. Wu L, Chaudhary SC, Atigadda VR, Belyaeva OV, Harville SR, Elmets CA, Muccio DD, Athar M and Kedishvili NY: Retinoid $\mathrm{X}$ receptor agonists upregulate genes responsible for the biosynthesis of all-trans-retinoic acid in human epidermis. PLoS One 11: e0153556, 2016.

10. Jacobson A, Johansson S, Branting M and Melhus H: Vitamin A differentially regulates RANKL and OPG expression in human osteoblasts. Biochem Biophys Res Commun 322: 162-167, 2004.

11. Michaëlsson K, Lithell H, Vessby B and Melhus H: Serum retinol levels and the risk of fracture. N Engl J Med 348: 287-294, 2003

12. Skillington J, Choy L and Derynck R: Bone morphogenetic protein and retinoic acid signaling cooperate to induce osteoblast differentiation of preadipocytes. J Cell Biol 159: 135-146, 2002.

13. Hisada K, Hata K, Ichida F, Matsubara T, Orimo H, Nakano T, Yatani H, Nishimura R and Yoneda T: Retinoic acid regulates commitment of undifferentiated mesenchymal stem cells into osteoblasts and adipocytes. J Bone Miner Metab 31: 53-63, 2013

14. Malladi P, Xu Y, Yang GP and Longaker MT: Functions of vitamin $\mathrm{D}$, retinoic acid, and dexamethasone in mouse adipose-derived mesenchymal cells. Tissue Eng 12: 2031-2040, 2006.

15. Mirsaidi A, Kleinhans KN, Rimann M, Tiaden AN, Stauber M, Rudolph KL and Richards PJ: Telomere length, telomerase activity and osteogenic differentiation are maintained in adipose-derived stromal cells from senile osteoporotic SAMP6 mice. J Tissue Eng Regen Med 6: 378-390, 2012.

16. Song HM, Nacamuli RP, Xia W, Bari AS, Shi YY, Fang TD and Longaker MT: High-dose retinoic acid modulates rat calvarial osteoblast biology. J Cell Physiol 202: 255-262, 2005.

17. Tiaden AN, Breiden M, Mirsaidi A, Weber FA, Bahrenberg G, Glanz S, Cinelli P, Ehrmann M and Richards PJ: Human serine protease HTRA1 positively regulates osteogenesis of human bone marrow-derived mesenchymal stem cells and mineralization of differentiating bone-forming cells through the modulation of extracellular matrix protein. Stem Cells 30: 2271-2282, 2012.

18. Wan DC, Shi YY, Nacamuli RP, Quarto N, Lyons KM and Longaker MT: Osteogenic differentiation of mouse adipose-derived adult stromal cells requires retinoic acid and bone morphogenetic protein receptor type IB signaling. Proc Natl Acad Sci USA 103: 12335-12340, 2006.

19. Wan DC, Siedhoff MT, Kwan MD, Nacamuli RP, Wu BM and Longaker MT: Refining retinoic acid stimulation for osteogenic differentiation of murine adipose-derived adult stromal cells. Tissue Eng 13: 1623-1631, 2007.

20. Choong PF, Martin TJ and Ng KW: Effects of ascorbic acid, calcitriol, and retinoic acid on the differentiation of preosteoblasts. J Orthop Res 11: 638-647, 1993.

21. Descalzi Cancedda F, Gentili C, Manduca P and Cancedda R: Hypertrophic chondrocytes undergo further differentiation in culture. J Cell Biol 117: 427-435, 1992.
22. Leboy PS, Beresford JN, Devlin C and Owen ME: Dexamethasone induction of osteoblast mRNAs in rat marrow stromal cell cultures. J Cell Physiol 146: 370-378, 1991.

23. Iba K, Chiba H, Yamashita T, Ishii $S$ and Sawada N: Phase-independent inhibition by retinoic acid of mineralization correlated with loss of tetranectin expression in a human osteoblastic cell line. Cell Struct Funct 26: 227-233, 2001.

24. Lind T, Sundqvist A, Hu L, Pejler G, Andersson G, Jacobson A and Melhus H: Vitamin a is a negative regulator of osteoblast mineralization. PLoS One 8: e82388, 2013.

25. Ohishi K, Nishikawa S, Nagata T, Yamauchi N, Shinohara H, Kido J and Ishida H: Physiological concentrations of retinoic acid suppress the osteoblastic differentiation of fetal rat calvaria cells in vitro. Eur J Endocrinol 133: 335-341, 1995.

26. Nallamshetty S, Wang H, Rhee EJ, Kiefer FW, Brown JD, Lotinun S, Le P, Baron R, Rosen CJ and Plutzky J: Deficiency of retinaldehyde dehydrogenase 1 induces BMP2 and increases bone mass in vivo. PLoS One 8: e71307, 2013.

27. Chen M, Huang HZ, Wang $M$ and Wang AX: Retinoic acid inhibits osteogenic differentiation of mouse embryonic palate mesenchymal cells. Birth Defects Res A Clin Mol Teratol 88: 965-970, 2010.

28. Xin M, Yang Y,Zhang D, Wang J, Chen S and Zhou D: Attenuation of hind-limb suspension-induced bone loss by curcumin is associated with reduced oxidative stress and increased vitamin D receptor expression. Osteoporos Int 26: 2665-2676, 2015.

29. Aggarwal BB, Sundaram C, Malani N and Ichikawa H: Curcumin: The Indian solid gold. Adv Exp Med Biol 595: 1-75, 2007.

30. Shishodia S, Sethi G and Aggarwal BB: Curcumin: Getting back to the roots. Ann N Y Acad Sci 1056: 206-217, 2005.

31. Riva A, Togni S, Giacomelli L, Franceschi F, Eggenhoffner R, Feragalli B, Belcaro G, Cacchio M, Shu H and Dugall M: Effects of a curcumin-based supplementation in asymptomatic subjects with low bone density: A preliminary 24-week supplement study. Eur Rev Med Pharmacol Sci 21: 1684-1689, 2017.

32. Lone J, Choi JH, Kim SW and Yun JW: Curcumin induces brown fat-like phenotype in 3T3-L1 and primary white adipocytes. J Nutr Biochem 27: 193-202, 2016.

33. Rohanizadeh R, Deng Y and Verron E: Therapeutic actions of curcumin in bone disorders. Bonekey Rep 5: 793, 2016.

34. Yun JW: Possible anti-obesity therapeutics from nature-a review. Phytochemistry 71: 1625-1641, 2010.

35. Cho DC, Jung HS, Kim KT, Jeon Y, Sung JK and Hwang JH: Therapeutic advantages of treatment of high-dose curcumin in the ovariectomized rat. J Korean Neurosurg Soc 54: 461-466, 2013.

36. Folwarczna J, Zych M and Trzeciak HI: Effects of curcumin on the skeletal system in rats. Pharmacol Rep 62: 900-909, 2010

37. Hussan F, Ibraheem NG, Kamarudin TA, Shuid AN, Soelaiman IN and Othman F: Curcumin protects against ovariectomy-induced bone changes in rat model. Evid Based Complement Alternat Med 2012: 174916, 2012.

38. Kim WK, Ke K, Sul OJ, Kim HJ, Kim SH, Lee MH, Kim HJ, Kim SY, Chung HT and Choi HS: Curcumin protects against ovariectomy-induced bone loss and decreases osteoclastogenesis. J Cell Biochem 112: 3159-3166, 2011.

39. Yang MW, Wang TH, Yan PP, Chu LW, Yu J, Gao ZD, Li YZ and Guo BL: Curcumin improves bone microarchitecture and enhances mineral density in APP/PS1 transgenic mice. Phytomedicine 18: 205-213, 2011.

40. French DL, Muir JM and Webber CE: The ovariectomized, mature rat model of postmenopausal osteoporosis: An assessment of the bone sparing effects of curcumin. Phytomedicine 15: 1069-1078, 2008

41. Kuncha M, Naidu VG, Sahu BD, Gadepalli SG and Sistla R: Curcumin potentiates the anti-arthritic effect of prednisolone in Freund's complete adjuvant-induced arthritic rats. J Pharm Pharmacol 66: 133-144, 2014.

42. Jain S, Meka SRK and Chatterjee K: Curcumin eluting nanofibers augment osteogenesis toward phytochemical based bone tissue engineering. Biomed Mater 11: 055007, 2016.

43. Aggarwal BB, Kumar A and Bharti AC: Anticancer potential of curcumin: Preclinical and clinical studies. Anticancer Res 23: 363-398, 2003.

44. Biswas S and Rahman I: Modulation of steroid activity in chronic inflammation: A novel anti-inflammatory role for curcumin. Mol Nutr Food Res 52: 987-994, 2008.

45. Goel A, Jhurani S and Aggarwal BB: Multi-targeted therapy by curcumin: how spicy is it? Mol Nutr Food Res 52: 1010-1030, 2008 . 
46. López-Lázaro M: Anticancer and carcinogenic properties of curcumin: Considerations for its clinical development as a cancer chemopreventive and chemotherapeutic agent. Mol Nutr Food Res 52 (Suppl 1): S103-S127, 2008.

47. Bharti AC, Takada Y and Aggarwal BB: Curcumin (diferuloylmethane) inhibits receptor activator of NF-kappa B ligand-induced NF-kappa B activation in osteoclast precursors and suppresses osteoclastogenesis. J Immunol 172: 5940-5947, 2004

48. Chan WH, Wu HY and Chang WH: Dosage effects of curcumin on cell death types in a human osteoblast cell line. Food Chem Toxicol 44: 1362-1371, 2006

49. Notoya M, Nishimura H, Woo JT, Nagai K, Ishihara $Y$ and Hagiwara H: Curcumin inhibits the proliferation and mineralization of cultured osteoblasts. Eur J Pharmacol 534: 55-62, 2006.

50. Ozaki K, Kawata Y, Amano S and Hanazawa S: Stimulatory effect of curcumin on osteoclast apoptosis. Biochem Pharmacol 59: $1577-1581,2000$

51. Von Metzler I, Krebbel H, Kuckelkorn U, Heider U, Jakob C, Kaiser M, Fleissner C, Terpos E and Sezer O: Curcumin diminishes human osteoclastogenesis by inhibition of the signalosome-associated I kappaB kinase. J Cancer Res Clin Oncol 135: 173-179, 2009

52. Yamaguchi M, Hamamoto R, Uchiyama S and Ishiyama $\mathrm{K}$ : Effects of flavonoid on calcium content in femoral tissue culture and parathyroid hormone-stimulated osteoclastogenesis in bone marrow culture in vitro. Mol Cell Biochem 303: 83-88, 2007.

53. Gu Q, Cai Y, Huang C, Shi Q and Yang H: Curcumin increases rat mesenchymal stem cell osteoblast differentiation but inhibits adipocyte differentiation. Pharmacogn Mag 8: 202-208, 2012.

54. Hou M, Song Y, Li Z, Luo C, Ou JS, Yu H, Yan J and Lu L: Curcumin attenuates osteogenic differentiation and calcification of rat vascular smooth muscle cells. Mol Cell Biochem 420: 151-160, 2016.

55. Chen F, Wang H, Xiang X, Yuan J, Chu W, Xue X, Zhu H, Ge H, Zou M, Feng $\mathrm{H}$ and Lin J: Curcumin increased the differentiation rate of neurons in neural stem cells via wnt signaling in vitro study. J Surg Res 192: 298-304, 2014.

56. Tiwari SK, Agarwal S, Seth B, Yadav A, Nair S, Bhatnagar P, Karmakar M, Kumari M, Chauhan LK, Patel DK, et al: Curcumin-loaded nanoparticles potently induce adult neurogenesis and reverse cognitive deficits in Alzheimer's disease mode via canonical Wnt/ $\beta$-catenin pathway. ACS Nano 8: 76-103, 2014

57. Tiwari SK, Agarwal S, Tripathi A and Chaturvedi RK: Bisphenol-A mediated inhibition of hippocampal neurogenesis attenuated by curcumin via canonical Wnt pathway. Mol Neurobiol 53: 3010-3029, 2016.

58. Cui L, Jia X, Zhou Q, Zhai X, Zhou Y and Zhu H: Curcumin affects $\beta \square$ catenin pathway in hepatic stellate cell in vitro and in vivo. J Pharm Pharmacol 66: 1615-1622, 2014.

59. He M, Li Y, Zhang L, Li L, Shen Y, Lin L, Zheng W, Chen L, Bian X, Ng HK and Tang L: Curcumin suppresses cell proliferation through inhibition of the Wnt $/ \beta$-catenin signaling pathway in medulloblastoma. Oncol Rep 32: 173-180, 2014.

60. Moran JM, Roncero-Martin R, Rodriguez-Velasco FJ, Calderon-Garcia JF, Rey-Sanchez P, Vera V, Canal-Macias ML and Pedrera-Zamorano JD: Effects of curcumin on the proliferation and mineralization of human osteoblast-like cells: Implications of nitric oxide. Int J Mol Sci 13: 16104-16118, 2012.

61. Oh S, Kyung TW and Choi HS: Curcumin inhibits osteoclastogenesis by decreasing receptor activator of nuclear factor-kappaB ligand (RANKL) in bone marrow stromal cells. Mol Cells 26 486-489, 2008

62. Vierbuchen T, Ostermeier A, Pang ZP, Kokubu Y, Südhof TC and Wernig M: Direct conversion of fibroblasts to functional neurons by defined factors. Nature 463: 1035-1041, 2010.

63. Ieda M, Fu JD, Delgado-Olguin P, Vedantham V, Hayashi Y, Bruneau BG and Srivastava D: Direct reprogramming of fibroblasts into functional cardiomyocytes by defined factors. Cell 142: 375-386, 2010

64. Sekiya S and Suzuki A: Direct conversion of mouse fibroblasts to hepatocyte-like cells by defined factors. Nature 475: 390-393, 2011

65. Li Y, Wang Y, Yu J, Ma Z, Bai Q, Wu X, Bao P, Li L, Ma D. Liu J, et al: Direct conversion of human fibroblasts into osteoblasts and osteocytes with small molecules and a single factor, Runx2. bioRxiv: 127480, 2017

66. Wang Y, Wu MH, Cheung MPL, Sham MH, Akiyama H, Chan D, Cheah KSE and Cheung M: Reprogramming of dermal fibroblasts into osteo-chondrogenic cells with elevated osteogenic potency by defined transcription factors. Stem Cell Reports 8: $1587-1599,2017$
67. Nam YJ, Song K, Luo X, Daniel E, Lambeth K, West K, Hill JA, DiMaio JM, Baker LA, Bassel-Duby R and Olson EN: Reprogramming of human fibroblasts toward a cardiac fate. Proc Natl Acad Sci USA 110: 5588-5593, 2013.

68. Qian L, Huang Y, Spencer CI, Foley A, Vedantham V, Liu L, Conway SJ, Fu JD and Srivastava D: In vivo reprogramming of murine cardiac fibroblasts into induced cardiomyocytes. Nature 485: 593-598, 2012

69. Minamide A, Boden SD, Viggeswarapu M, Hair GA, Oliver C and Titus L: Mechanism of bone formation with gene transfer of the cDNA encoding for the intracellular protein LMP-1. J Bone Joint Surg Am 85-A: 1030-1039, 2003.

70. Salgia R, Li JL, Lo SH, Brunkhorst B, Kansas GS, Sobhany ES, Sun Y, Pisick E, Hallek M, Ernst T, et al: Molecular cloning of human paxillin, a focal adhesion protein phosphorylated by P210BCR/ABL. J Biol Chem 270: 5039-5047, 1995.

71. Lattanzi W, Barba M, Novegno F, Massimi L, Tesori V, Tamburrini G, Galgano S, Bernardini C, Caldarelli M, Michetti F and Di Rocco C: Lim mineralization protein is involved in the premature calvarial ossification in sporadic craniosynostoses. Bone 52: 474-484, 2013

72. Lattanzi W, Parrilla C, Fetoni A, Logroscino G, Straface G, Pecorini G, Stigliano E, Tampieri A, Bedini R, Pecci R, et al: Ex vivo-transduced autologous skin fibroblasts expressing human Lim mineralization protein-3 efficiently form new bone in animal models. Gene Ther 15: 1330-1343, 2008.

73. Yoon ST and Boden SD: Spine fusion by gene therapy. Gene Ther 11: 360-367, 2004.

74. Soleimani M and Nadri S: A protocol for isolation and culture of mesenchymal stem cells from mouse bone marrow. Nat Protoc 4: 102-106, 2009.

75. Pola E, Gao W, Zhou Y, Pola R, Lattanzi W, Sfeir C, Gambotto A and Robbins PD: Efficient bone formation by gene transfer of human LIM mineralization protein-3. Gene Ther 11: 683-693, 2004.

76. Huang S, Xu L, Sun Y, Wu T, Wang K and Li G: An improved protocol for isolation and culture of mesenchymal stem cells from mouse bone marrow. J Orthop Translat 3: 26-33, 2014.

77. Zhang T, Lee YW, Rui YF, Cheng TY, Jiang XH and Li G: Bone marrow-derived mesenchymal stem cells promote growth and angiogenesis of breast and prostate tumors. Stem Cell Res Ther 4: 70, 2013

78. Chang R, Sun L and Webster TJ: Short communication: Selective cytotoxicity of curcumin on osteosarcoma cells compared to healthy osteoblasts. Int J Nanomedicine 9: 461-465, 2014.

79. Wang N, Wang F, Gao Y, Yin P, Pan C, Liu W, Zhou Z and Wang J: Curcumin protects human adipose-derived mesenchymal stem cells against oxidative stress-induced inhibition of osteogenesis. J Pharmacol Sci 132: 192-200, 2016.

80. Bi W, Gu Z, Zheng Y, Wang L, Guo J and Wu G: Antagonistic and synergistic effects of bone morphogenetic protein $2 / 7$ and all-trans retinoic acid on the osteogenic differentiation of rat bone marrow stromal cells. Dev Growth Differ 55: 744-754, 2013.

81. Sheng N, Xie Z, Wang C, Bai G, Zhang K, Zhu Q, Song J, Guillemot F, Chen YG, Lin A and Jing N: Retinoic acid regulates bone morphogenic protein signal duration by promoting the degradation of phosphorylated Smad1. Proc Natl Acad Sci USA 107: 18886-18891, 2010

82. Wang A, Ding X, Sheng S and Yao Z: Retinoic acid inhibits osteogenic differentiation of rat bone marrow stromal cells. Biochem Biophys Res Commun 375: 435-439, 2008.

83. Yamamoto K, Kishida T, Sato Y, Nishioka K, Ejima A, Fujiwara H, Kubo T, Yamamoto T, Kanamura N and Mazda O: Direct conversion of human fibroblasts into functional osteoblasts by defined factors. Proc Natl Acad Sci USA 112: 6152-6157, 2015.

84. Livak KJ and Schmittgen TD: Analysis of relative gene expression data using real-time quantitative PCR and the 2(-Delta Delta C(T)) method. Methods 25: 402-408, 2001.

85. Schindelin J, Arganda-Carreras I, Frise E, Kaynig V, Longair M, Pietzsch T, Preibisch S, Rueden C, Saalfeld S, Schmid B, et al: Fiji: An open-source platform for biological-image analysis. Nat Methods 9: 676-682, 2012.

86. Ahmed MF, El-Sayed AK, Chen H, Zhao R, Jin K, Zuo Q, Zhang Y and Li B: Direct conversion of mouse embryonic fibroblast to osteoblast cells using hLMP-3 with Yamanaka factors. Int J Biochem Cell Biol 106: 84-95, 2019.

87. James AW, Levi B, Xu Y, Carre AL and Longaker MT: Retinoic acid enhances osteogenesis in cranial suture-derived mesenchymal cells: Potential mechanisms of retinoid-induced craniosynostosis. Plast Reconstr Surg 125: 1352-1361, 2010. 
88. Green AC, Kocovski P, Jovic T, Walia MK, Chandraratna RAS, Martin TJ, Baker EK and Purton LE: Retinoic acid receptor signalling directly regulates osteoblast and adipocyte differentiation from mesenchymal progenitor cells. Exp Cell Res 350: 284-297, 2017.

89. Zhang S, Chen X, Hu Y, Wu J, Cao Q, Chen S and Gao Y: All-trans retinoic acid modulates Wnt3A-induced osteogenic differentiation of mesenchymal stem cells via activating the PI3K/AKT/GSK3 $\beta$ signalling pathway. Mol Cell Endocrinol 422: 243-253, 2016.

90. Ding J, Woo JT and Nagai K: The effects of retinoic acid on reversing the adipocyte differentiation into an osteoblastic tendency in ST2 cells, a murine bone marrow-derived stromal cell line. Cytotechnology 36: 125-136, 2001.

91. Cohen-Tanugi A and Forest N: Retinoic acid suppresses the osteogenic differentiation capacity of murine osteoblast-like 3/A/1D-1M cell cultures. Differentiation 63: 115-123, 1998.

92. Son HE, Kim EJ and Jang WG: Curcumin induces osteoblast differentiation through mild-endoplasmic reticulum stress-mediated such as BMP2 on osteoblast cells. Life Sci 193: 34-39, 2018.

93. Eghbali-Fatourechi G, Khosla S, Sanyal A, Boyle WJ, Lacey DL and Riggs BL: Role of RANK ligand in mediating increased bone resorption in early postmenopausal women. J Clin Invest 111: $1221-1230,2003$
94. Li Y, Li A, Strait K, Zhang H, Nanes MS and Weitzmann MN: Endogenous TNFalpha lowers maximum peak bone mass and inhibits osteoblastic Smad activation through NF-kappaB. J Bone Miner Res 22: 646-655, 2007.

95. Chang J, Wang Z, Tang E, Fan Z, McCauley L, Franceschi R, Gaun K, Krebsbach PH and Wang CY: Inhibition of osteoblast functions by IKK/NF- $\mathrm{BB}$ in osteoporosis. Nat Med 15: 682-689, 2009.

96. Zhang X, Yin WK, Shi XD and Li Y: Curcumin activates Wnt/ $\beta$-catenin signaling pathway through inhibiting the activity of GSK-3 $\beta$ in APPswe transfected SY5Y cells. Eur J Pharm Sci 42: 540-546, 2011

97. Thacker PC and Karunagaran D: Curcumin and emodin down-regulate TGF- $\beta$ signaling pathway in human cervical cancer cells. PLoS One 10: e0120045, 2015.

(i) () () This work is licensed under a Creative Commons Attribution-NonCommercial-NoDerivatives 4.0 International (CC BY-NC-ND 4.0) License. 